\section{Brazilian Journal \\ of Chemical \\ Engineering}

ISSN 0104-6632

Printed in Brazil

www.scielo.br/bjce

Vol. 35, No. 01, pp. 147 - 154, January - March, 2018

(cc) BY

dx.doi.org/10.1590/0104-6632.20180351s20160504

\title{
CE/KAOLIN CLAY AS AN ACTIVE CATALYST FOR FATTY ACID METHYL ESTERS PRODUCTION FROM COTTONSEED OIL IN A NEW INTEGRATED APPARATUS
}

\author{
Junwei Liu ${ }^{1}$, Zhi Yun ${ }^{1, *}$ and Xia Gui ${ }^{1}$ \\ ${ }^{1}$ College of Chemistry and Chemical Engineering, Nanjing Tech University, Nanjing 210009, P. R. China
}

(Submitted: August 23, 2016; Revised: October 5, 2016; Accepted: October 10, 2016)

\begin{abstract}
An efficient solid acid catalyst (Ce/Kaolin clay) was prepared and investigated for transesterification of cottonseed oil to fatty acid methyl esters (FAME). The catalysts were characterized by XRD, BET, and $\mathrm{NH}_{3}-\mathrm{TPD}$ measurements. A new integrated apparatus for extraction and transesterification of cottonseed oil was developed. The effects of cerium loading, catalyst calcination temperature, methanol flow rate, reaction temperature, reaction time, and catalyst amount were also investigated. The results indicated that the Ce/Kaolin clay showed high catalytic activity under the calcination temperature of $700{ }^{\circ} \mathrm{C}$ and cerium loading of $0.05 \mathrm{~g} / \mathrm{g}$. The optimum transesterification reaction conditions were as follows: methanol flow rate $4.0 \mathrm{~mL} / \mathrm{min}$, reaction temperature $60{ }^{\circ} \mathrm{C}$, reaction time $3 \mathrm{~h}$, and catalyst amount $15 \mathrm{~g}$. Under these conditions, the yield of FAME was up to $91 \%$. The catalytic activity of Ce/Kaolin clay still remained high after 4 times of repeated use. The results indicated that the Ce/Kaolin clay catalysts had a good potential for use in the large-scale production of FAME.
\end{abstract}

Keywords: Ce/Kaolin clay, integrated apparatus, transesterification, fatty acid methyl esters, cottonseed oil

\section{INTRODUCTION}

Due to the limited fossil fuel resources and increasing environmental problems, great efforts have been dedicated to developing renewable biomass and biofuels. In this context, fatty acid methyl esters (FAME) are considered as a promising substitute to traditional fossil fuels due to their renewable, environmentally benign, and carbon neutral characteristics (Kumar and Ali, 2014). FAME are generally produced from vegetable oils or animal fats. In the industrial transesterification process, base or acid catalysts such as sodium hydroxide $(\mathrm{NaOH})$ (Semwal et al., 2011) and sulfuric acid $\left(\mathrm{H}_{2} \mathrm{SO}_{4}\right)$ (Moradi et al., 2013) are used as the catalysts. The advantage of this technology is that high FAME yield can be obtained under moderate reaction conditions. However, homogeneous catalysts show many drawbacks, such as difficulty to be reused, complicated process of post treatment, and serious environmental problems (Guo et al., 2013).

In contrast, heterogeneous catalysts exhibit many advantages, such as environmentally friendly, easy separation, and simple post treatments. The transesterification reaction can be conducted over solid acid or base catalyst. Although the transesterification rate over the base catalysts is faster, the activity of base sites is reduced after neutralization with fatty acid during the alkaline-metal-hydroxide-catalyzed transesterification. Furthermore, the water and the fatty acids can form soap. Therefore, we investigated the transesterification reaction of cottonseed oil over solid acid catalysts.

Kaolin clay is a cheap and versatile raw material which can be found in numerous geographical locations and has 
been used successfully in the synthesis of mesoporous aluminosilicates (Liu et al., 2004) and various microporous zeolite frameworks (Belviso et al., 2013; Holmes et al., 2012; Holmes et al., 2011; Kovo et al., 2009; Shen et al., 2009). However, raw Kaolin clay has almost no acidity. To improve the acidity of the bare Kaolin clay, adding some elements into its framework is essential. Many researchers have reported that modified Kaolin clay catalysts can catalyze vegetable oils with methanol to produce FAME (Dang et al., 2013). To the best of our knowledge, no scientific papers have been published on the use of $\mathrm{Ce} /$ Kaolin clay as catalyst for the production of FAME.

A new integrated apparatus for extraction and transesterification of cottonseed oil was developed to produce FAME (Figure 1 and 2). The experiment was performed in a tower reactor equipped with a water-cooled condenser. A certain amount of cottonseed kernel powder was loaded in the accumulator tank at the top of the tower, and the catalysts supported on theta $(\theta)$ packing rings $(\phi$ $3 \times 3$ were loaded in the tower body. The catalyst amounts were varied by changing the tower section numbers. Then, desired amount of methanol was pumped to the top of the tower and the cottonseed oil was successfully extracted from the cottonseed kernel powder. It should be noted that the separation and purification process was not conducted after the extraction process. The excess extraction solvent and cottonseed oil flowed into the transesterification reactor. In that case, the methanol acted as reactant in the transesterification reaction. Finally, the FAME can be collected from the outlet of the reaction device. The extraction and transesterification of cottonseed oil were both performed in this integrated apparatus, which can simplify the process and decrease costs significantly.

This paper represents an extension of our previous research and provides a new synthetic route of cottonseedbased FAME (Qian et al., 2010; Cao et al., 2014; Zhu et al., 2014; Gui et al., 2016; Gui et al., 2016). In this study, we introduced cerium on the Kaolin clay to improve the catalyst acidity, and studied its catalytic performance for the transesterification of cottonseed oil to FAME in a new integrated apparatus. The catalysts were characterized by XRD, BET and $\mathrm{NH}_{3}$-TPD measurements. The effects of cerium loading, catalyst calcination temperature, methanol flow rate, reaction temperature, reaction time, and catalyst amount were also examined.

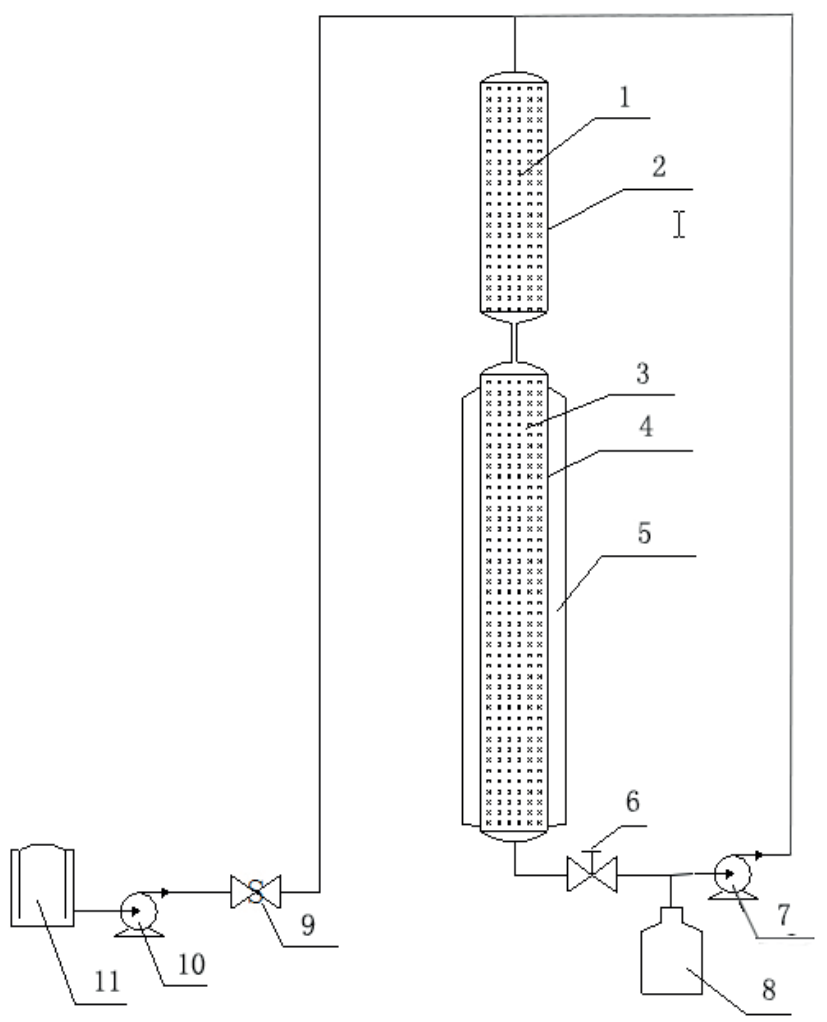

Figure 2. Scheme of the integrated apparatus for FAME production. 1-cottonseed kernel powder; 2-accumulator tank; 3-random packing; 4-column reactor; 5-water bath; 6,9-check valve; 7,10-plunger pump; 8-FAME tank; 11-methanol tank

\section{MATERIALS AND METHODS}

\section{Materials}

Cottonseeds were obtained from Huaian (Jiangsu, China). Methanol (Aladdin, 99.9\%), Kaolin clay, $\mathrm{Ce}\left(\mathrm{SO}_{4}\right)_{2} \cdot 4 \mathrm{H}_{2} \mathrm{O}$ (Aladdin, 99\%), and $\mathrm{H}_{2} \mathrm{SO}_{4}$ (Aladdin, $37 \%$ ) were purchased from Nanjing Wanqing Chemical Co., Ltd. (Nanjing, China). All of the chemicals used in this work were of analytical reagent grade.

\section{Methods}

The industrial grade cottonseeds were dried at $110{ }^{\circ} \mathrm{C}$ for $24 \mathrm{~h}$, then milled into a fine powder using an electric grinder and sifted through a 60-mesh screen sieve.

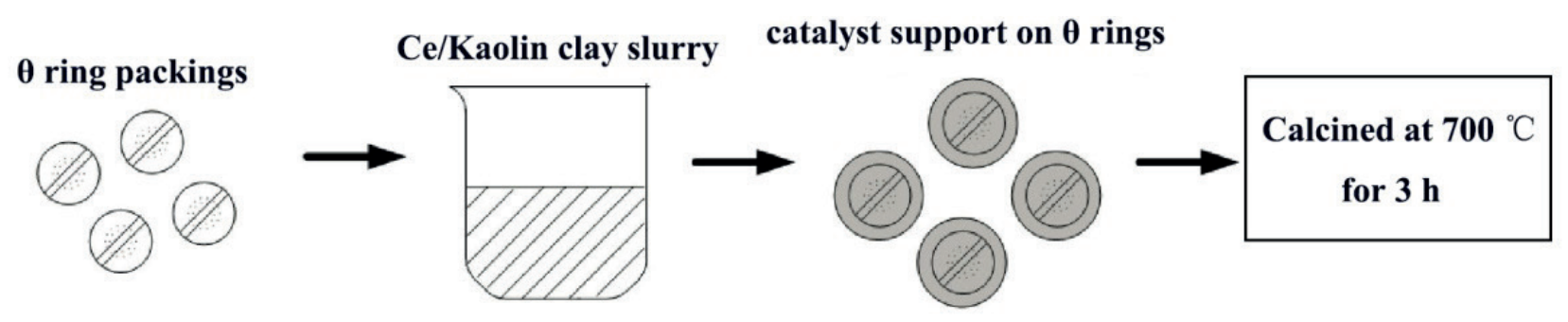

Figure 1. Preparation of the catalyst supported on $\theta$ packing rings. 
According to the ISO 659-1988 and GB/T 14489.1-2008/ ISO 665:2000 standards, the oil, moisture and free gossypol contents of the milled cottonseed were $35.4 \mathrm{~g} / \mathrm{g}$ (wet basis), $6.9 \mathrm{~g} / \mathrm{g}$ and $0.309 \mathrm{~g} / \mathrm{g}$, respectively.

The Ce/Kaolin clay catalysts were prepared by a conventional wet impregnation method (Alves et al., 2014). First, $10 \mathrm{~g}$ of Kaolin clay was added into $20 \mathrm{~mL}$ of distilled water under stirring. Afterwards, sulfuric acid was added dropwise until the $\mathrm{pH}$ reached 3 with constant magnetic stirring at room temperature. Meanwhile, a certain amount of $\mathrm{Ce}\left(\mathrm{SO}_{4}\right)_{2} \cdot 4 \mathrm{H}_{2} \mathrm{O}$ was dissolved in the resultant slurry at room temperature for $24 \mathrm{~h}$. Then, the mixture slurry was supported on the packing ring, dried at $110^{\circ} \mathrm{C}$ for $12 \mathrm{~h}$, and finally calcined in air for $3 \mathrm{~h}$. The modified Kaolin clay samples were denoted as $\mathrm{xCe} / \mathrm{Kaolin}$ clay $(\mathrm{x}=0-10$ mass $\%$ (g/100 g) of Ce loading). The as-prepared catalysts were stored in a desiccators before catalytic tests.

First, $200 \mathrm{~g}$ of cottonseed kernel powder was loaded in the accumulator tank at the top of the tower. Next 15 $\mathrm{g}$ of catalysts (including the theta packing rings) were preheated in a mixing column with random packing in the tower body. The reaction temperature was controlled at $60{ }^{\circ} \mathrm{C}$ by a water bath. Then, $200 \mathrm{~mL}$ of methanol was pumped into the top of the tower from the methanol tank and the cottonseed oil was successfully extracted from the cottonseed kernel powder. Afterwards, the excess extraction solvent and cottonseed oil flowed into the transesterification reactor. In that case, the methanol acted as reactant in the transesterification reaction. When the methanol was exhausted, the check valve 7 was opened, then the unreacted methanol and cottonseed oil was continually pumped into the reaction system for circular reaction. Therefore, both the utilization of methanol and the conversion of cottonseed oil were increased. Finally, the FAME can be collected from the outlet of the reaction device.

The procedure was conducted under different reaction conditions: reaction time $(1-10 \mathrm{~h})$, reaction temperature $\left(40-80^{\circ} \mathrm{C}\right)$, methanol flow rate $(2-5 \mathrm{~mL} / \mathrm{min})$, and catalyst amount (5-20 g). The obtained reaction mixture was kept in the separating funnel for $12 \mathrm{~h}$ to separate the glycerol. After that, the excess methanol was removed from the reaction products using a rotary evaporator. To ensure the complete removal of the methanol, the evaporation process was conducted until the weight of samples remained unchanged (Kuk et al., 2005). The products were analyzed by gas chromatography (GC) following the previous literature (Molina Mayo et al., 2015).

\section{Catalyst Characterization}

The powder X-ray diffractions (XRD) were conducted on a Shimadzu XRD-6000 powder diffractometer with $\mathrm{Cu} K \alpha$-ray radiation $(\lambda=0.154 \mathrm{~nm})(40 \mathrm{kV}, 40 \mathrm{~mA})$. The diffraction patterns of the samples were recorded from $2 \theta$ $=10-90^{\circ}$ at a scanning speed of $20^{\circ} / \mathrm{min}$.
Temperature programmed desorption of ammonia $\left(\mathrm{NH}_{3}-\mathrm{TPD}\right)$ was used to test the acidity of the samples. 0.1 g catalyst was pretreated in $\mathrm{He}(40 \mathrm{~mL} / \mathrm{min})$ at $500{ }^{\circ} \mathrm{C}$ for $1 \mathrm{~h}$, and the sample was treated with ammonia after cooling down to $100{ }^{\circ} \mathrm{C}$. Then, the catalyst was purged with $\mathrm{He}$. Finally, $\mathrm{NH}_{3}$-TPD experiments were conducted in He from 100 to $700{ }^{\circ} \mathrm{C}$ at a heating rate of $20^{\circ} \mathrm{C} / \mathrm{min}$, then the $\mathrm{NH}_{3}-$ TPD data could be collected.

Brunauer-Emmett-Teller (BET) surface area analysis was conducted to characterize the specific surface area and pore size distribution of the samples. Analysis was conducted using a Quantachrome Autosorb-1 with nitrogen adsorption-desorption at $-196^{\circ} \mathrm{C}$. The degasification was performed under vacuum at $200{ }^{\circ} \mathrm{C}$ for $2 \mathrm{~h}$ before the adsorption measurements.

The reaction products were analyzed using a GC6890 gas chromatograph equipped with a flame ionization detector (FID) and AT.SE-30 capillary column $(50 \mathrm{~m}$ $\times 0.53 \mathrm{~mm} \times 3 \mu \mathrm{m})$. Methyl salicylate was used as an internal standard and $\mathrm{n}$-hexane as solvent. $1 \mathrm{~mL}$ of product was dissolved in $0.2 \mathrm{~mL}$ of methyl salicylate and $8 \mathrm{~mL}$ of $\mathrm{n}$-hexane with vigorous stirring. $1 \mu \mathrm{L}$ of the mixture was injected into the GC. The column temperature was $180^{\circ} \mathrm{C}$, the temperature of injector and detector were $260{ }^{\circ} \mathrm{C}$. The flow rates of hydrogen, nitrogen, and air were 40,19 , and $300 \mathrm{~mL} / \mathrm{min}$, respectively.

In the chromatographic operation conditions, a typical chromatogram is shown in Figure 3. According to Figure 3 , the order of peaks corresponds to the solvent n-hexane, methyl salicylate, methyl palmitate, methyl oleate, and linoleic acid methyl ester, respectively.

The yield of FAME was calculated as follows:

$$
B(\%)=\frac{S_{2} \times f^{\prime} \times m_{2}}{S_{1} \times m_{1}} \times 100
$$

where: $m_{1}$ is the mass of FAME, $m_{2}$ is the mass of internal standard added to the sample, $S_{1}$ is the peak area of internal standard, $S_{2}$ is the peak area of FAME, $f^{\prime}$ is the correction factor.

\section{RESULTS AND DISCUSSION}

\section{Catalyst Characterization}

The XRD patterns of the Ce/Kaolin clay catalysts calcined at $700{ }^{\circ} \mathrm{C}$ with different Ce loadings are shown in Figure 4. It is obvious that all samples show a very strong peak at about $2 \theta=26.08^{\circ}$, which is commonly attributed to the formation of amorphous phase of $\mathrm{SiO}_{2}$. Moreover, three weak peaks are also observed at $2 \theta=16.34^{\circ}, 35.20^{\circ}$ and $40.82^{\circ}$. These peaks confirm the triclinic structure which is the typical characteristic of Kaolin clay materials. In addition, the peak at $2 \theta=28.52^{\circ}$ is obviously observed on the $\mathrm{Ce} / \mathrm{Kaolin}$ clay catalysts, which corresponds to 


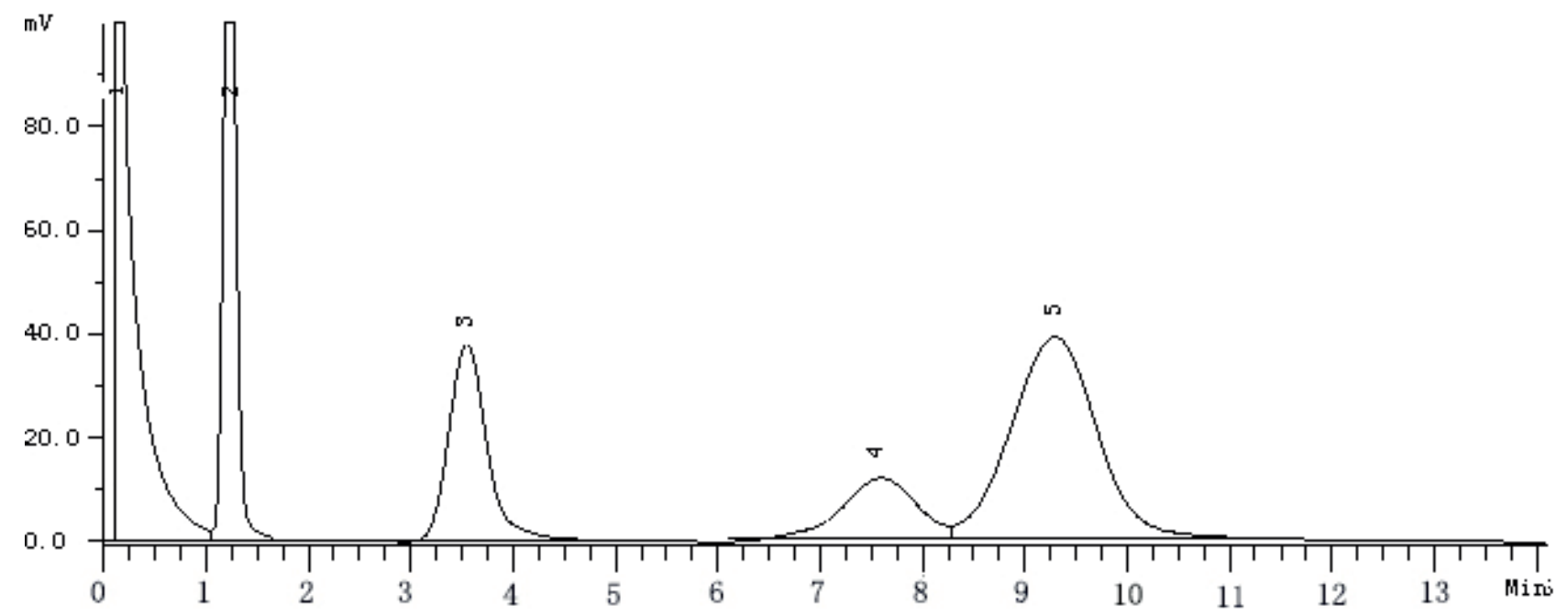

Figure 3. Chromatogram of the product.

the indexed $\mathrm{CeO}_{2}$ cubic system, unit cell and cubic face centered space group (Nascimento et al., 2015; Nascimento et al., 2014). The results indicate that Ce is successfully incorporated into the Kaolin clay support. It is worth noting that the intensity of the peak increases gradually when the cerium loading increases from 0.025 to $0.1 \mathrm{~g} / \mathrm{g}$, which is due to a large amount of $\mathrm{Ce}$ on the support. Moreover, when the cerium loading is up to $0.1 \mathrm{~g} / \mathrm{g}$, a strong peak is observed at $2 \theta=47.48^{\circ}$, suggesting that part of the cerium crystal structure is changed.

The physical properties of the catalysts play an important role during the transesterification reaction (Dang et al., 2013). The specific surface area, pore volume and pore size of the samples were examined, and the results are shown in Table 1. The surface area of the raw Kaolin clay is $8.91 \mathrm{~m}^{2} / \mathrm{g}$, and the surface areas of the $2.5 \mathrm{Ce}-\mathrm{Kaolin}$ clay, 5Ce-Kaolin clay, 7.5Ce-Kaolin

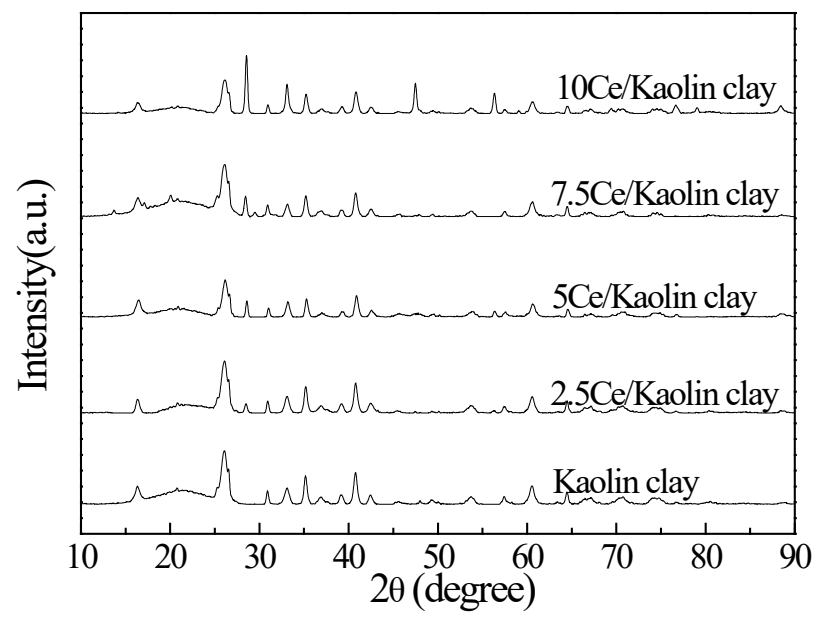

Figure 4. X-ray diffraction patterns of $\mathrm{Ce} / \mathrm{Kaolin}$ clay with different Ce loadings. clay and 10Ce-Kaolin clay are $8.70 \mathrm{~m}^{2} / \mathrm{g}, 8.13 \mathrm{~m}^{2} / \mathrm{g}, 7.27$ $\mathrm{m}^{2} / \mathrm{g}$, and $5.38 \mathrm{~m}^{2} / \mathrm{g}$, respectively. It is observed that the surface area of the catalysts decreases with increasing cerium loadings, which is due to the fact that the cerium is deposited on the Kaolin clay support. Furthermore, it can be seen that the pore volume decreases and the pore diameter increases with increasing cerium loadings. In fact, the size of triglycerides is estimated at around 3-5 $\mathrm{nm}$, which is much smaller than that of the modified Kaolin clay catalysts (López Granados et al., 2007). Therefore, the diffusion restriction of triglyceride molecules into pores and cages of the modified Kaolin clay catalysts can be avoided. Certainly, larger pore size is beneficial for reactant/product molecules to diffuse to the active sites, thus improving the catalytic activity of the catalysts (Wong et al., 2015).

The $\mathrm{NH}_{3}$-TPD profiles of the modified Kaolin clay catalysts are shown in Figure 5. It is obvious that the catalysts exhibit a weak peak from $150{ }^{\circ} \mathrm{C}$ to about $350{ }^{\circ} \mathrm{C}$ and a strong peak from $550^{\circ} \mathrm{C}$ to about $700{ }^{\circ} \mathrm{C}$, suggesting that the catalysts have weak and strong acid sites. With the increase of the cerium loading from 0 to $0.05 \mathrm{~g} / \mathrm{g}$, the intensities of the corresponding peaks increase, indicating that the acidity of the catalysts increases gradually. The increased acidity is due to dispersed cerium on Kaolin clay and the acidity can be adjusted by loading different amounts of cerium. In addition, the result also shows that the maximum acidity is achieved when the cerium loading is $0.05 \mathrm{~g} / \mathrm{g}$. However, the acidity of the catalysts decreases when the cerium loading is over $0.05 \mathrm{~g} / \mathrm{g}$, which is due to active sites of the catalysts being covered with excess cerium. It is noteworthy that the acidity of the catalysts has a great impact on the catalytic activity during the transesterification reaction. 
Table 1. Surface Characteristics of Raw and Modified Kaolin Clay Catalysts.

\begin{tabular}{lccc}
\hline Catalyst & Surfacearea $\left(\mathbf{m}^{2} / \mathbf{g}\right)$ & Porevolume $\left(\mathbf{c m}^{3} / \mathbf{g}\right)$ & Poresize(nm) \\
\hline Kaolin clay & 8.91 & 0.043 & 19.24 \\
2.5Ce/Kaolin clay & 8.70 & 0.040 & 19.82 \\
5 Ce/Kaolin clay & 8.13 & 0.033 & 21.53 \\
7.5 Ce/Kaolin clay & 7.27 & 0.025 & 26.94 \\
10Ce/Kaolin clay & 5.38 & 0.018 & 35.66 \\
\hline
\end{tabular}

\section{Effect of Cerium Loading on FAME Yield}

The FAME yields over the modified Kaolin clay catalysts were investigated by adjusting the cerium loading. The cerium loading ranging from 0 to $0.1 \mathrm{~g} / \mathrm{g}$ has a significant effect on the catalytic activity. The catalytic results are shown in Figure 4. It can be seen that bare Kaolin clay catalyst show low FAME yield (35\%). This is likely due to the fact that bare Kaolin clay show low acidity which can be seen in Figure 6; thus, the transesterification reaction cannot be achieved. Surprisingly, it is obvious that the modified Kaolin clay catalysts are more active. As the cerium loading increases, the acidity of the catalyst enhances, thus the FAME yield is increased significantly. In addition, the results also show that the maximum FAME yield $(88 \%)$ is obtained with $0.05 \mathrm{~g} / \mathrm{g}$ cerium loading, since the $5 \mathrm{Ce} / \mathrm{Kaolin}$ clay has more acidity compared to the other catalysts. However, when the cerium loading increased further, the FAME yield droped rapidly. This might be because the specific surface area, pore volume and acidity of the catalysts decrease when the cerium loading is over $0.05 \mathrm{~g} / \mathrm{g}$. Thus, the cerium loading was fixed at $0.05 \mathrm{~g} / \mathrm{g}$.

\section{Effect of Catalyst Calcination Temperature on FAME Yield}

The influence of the calcination temperature ranging from $500{ }^{\circ} \mathrm{C}$ to $900{ }^{\circ} \mathrm{C}$ for the transesterification of cottonseed oil over $5 \mathrm{Ce} / \mathrm{Kaolin}$ clay was investigated,

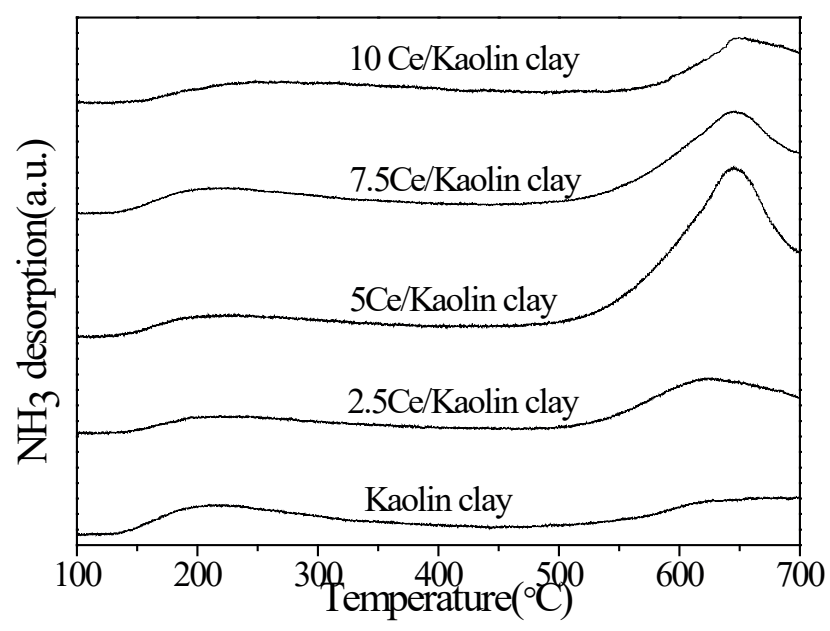

Figure 5. $\mathrm{NH}_{3}-\mathrm{TPD}$ spectra of raw and modified Kaolin clay catalysts. as shown in Figure 7. It is obvious that the catalytic activity of the $5 \mathrm{Ce} / \mathrm{Kaolin}$ clay is related to the catalyst calcination temperature. When the catalyst calcination temperature increases from 500 to $700{ }^{\circ} \mathrm{C}$, the FAME yield shows a rapid increase from 60 to $90 \%$. However, the yield of FAME decreases upon increasing the calcination temperature further, which may indicate that the $\mathrm{Ce} /$ Kaolin clay catalyst tends to decompose when calcined at high temperature. Therefore, $700{ }^{\circ} \mathrm{C}$ is the most suitable calcination temperature for $\mathrm{Ce} / \mathrm{Kaolin}$ clay for the transesterification reaction.

\section{Effect of Dosage of Methanol on Cottonseed Oil Extraction}

It is well known that commercial methanol is an efficient solvent for extracting oil from oilseeds. The dosage of methanol used is an important parameter during the extraction of cottonseed oil. The dosage of the methanol is controlled by adjusting the flow rate of methanol. The flow rate of methanol from 2.0 to $5.0 \mathrm{~mL} / \mathrm{min}$ was studied, and the results are shown in Figure 8. The extraction rate of cottonseed oil increases with the increase of the dosage of methanol from 2.0 to $4.0 \mathrm{~mL} / \mathrm{min}$, and the extraction time

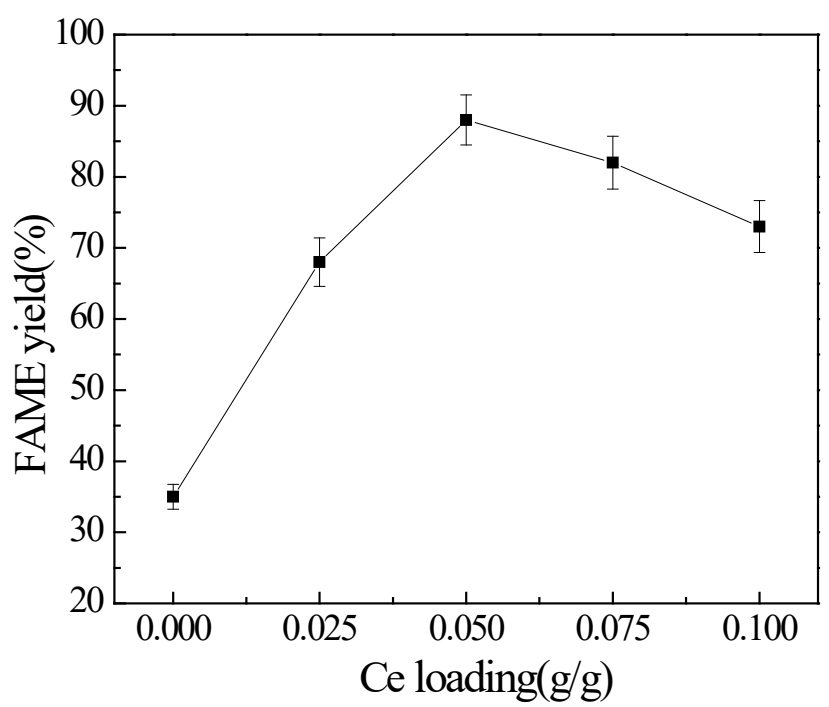

Figure 6. Influence of cerium loading on FAME yield. Reaction conditions: $200 \mathrm{~g}$ of cottonseed kernel powder, $15 \mathrm{~g}$ of catalyst, 5 $\mathrm{mL} / \mathrm{min}$ methanol phase rate, and reaction temperature $=50^{\circ} \mathrm{C}$. 


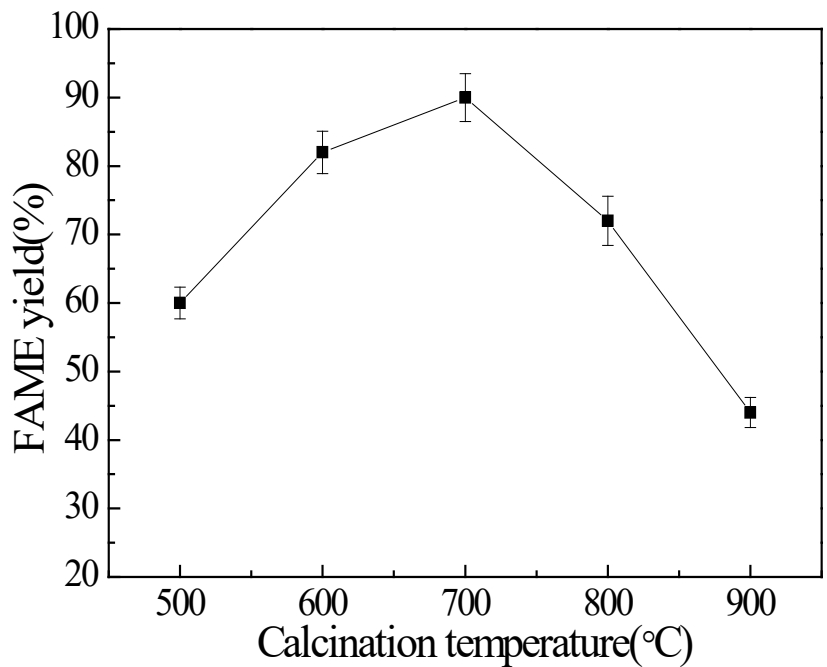

Figure 7. Influence of catalyst calcination temperature on FAME yield. Reaction conditions: $200 \mathrm{~g}$ of cottonseed kernel powder, $15 \mathrm{~g}$ of catalyst, $5 \mathrm{~mL} / \mathrm{min}$ methanol phase rate, and reaction temperature $=50{ }^{\circ} \mathrm{C}$.

reduces with the increasing dosage of methanol. When the flow rate of methanol reaches $4.0 \mathrm{~mL} / \mathrm{min}$, the extraction rate of cottonseed oil is $96.3 \%$ after $3 \mathrm{~h}$ of extraction. It is evident from Figure 8 that the excess methanol added to the reaction has a slight effect on the yield of cottonseed oil. Thus, the optimum methanol flow rate is $4.0 \mathrm{~mL} / \mathrm{min}$ and the extraction time is $3 \mathrm{~h}$.

\section{Effect of Dosage of Methanol on FAME Yield}

In order to study the optimum methanol dosage for the transesterification reaction, the effect of different molar ratio of the alcohol to oil by adjusting the flow rate of methanol from 2.0 to $5.0 \mathrm{~mL} / \mathrm{min}$ over $5 \mathrm{Ce} / \mathrm{Kaolin}$ clay was investigated, as shown in Figure 9. From the results, the FAME yield enhances gradually upon increasing the methanol flow rate from 2.0 to $4.0 \mathrm{~mL} / \mathrm{min}$. It can be seen that no obvious increase of FAME yield is observed upon increasing the methanol flow rate to $5.0 \mathrm{~mL} / \mathrm{min}$. Therefore, the optimum methanol flow rate is $4.0 \mathrm{~mL} / \mathrm{min}$ in this transesterification reaction. Moreover, the excess alcohol during the transesterification reaction was recovered by distillation and reused in the next reaction cycle.

\section{Effect of Reaction Temperature on FAME Yield}

The reaction temperature is found to have a considerable influence on the yield of FAME (Demirbas, 2009).To investigate the optimum temperature for the transesterification reaction, a series of reactions over $5 \mathrm{Ce} /$ Kaolin clay were performed by changing the temperature from 40 to $70{ }^{\circ} \mathrm{C}$ (Figure 10). From Figure 10, it is clearly seen that the yield of FAME noticeably increases with the reaction temperature increase from 40 to $70^{\circ} \mathrm{C}$. However,

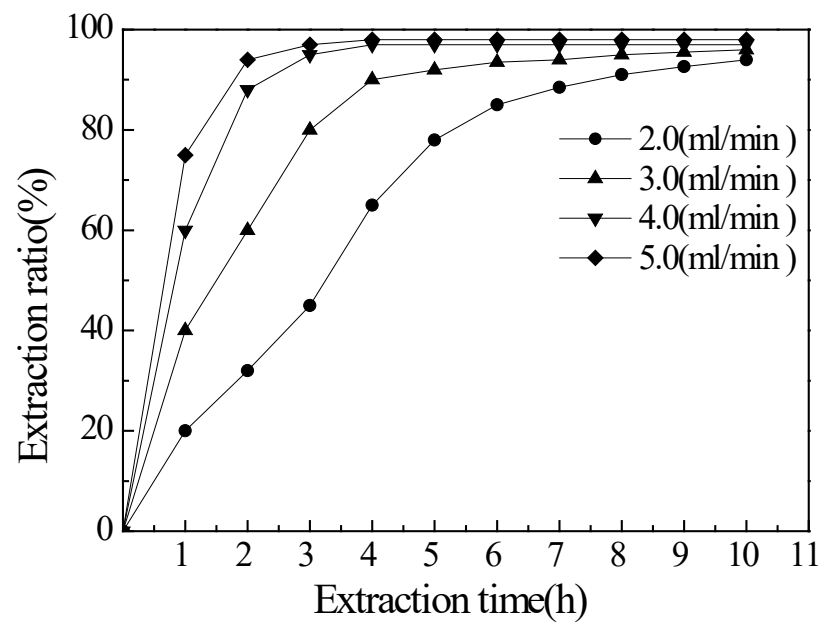

Figure 8. Influence of dosage of methanol on cottonseed oil extraction. Reaction conditions: $200 \mathrm{~g}$ of cottonseed kernel powder, ambient temperature, and $10 \mathrm{~h}$ of extraction time.

when the reaction temperature reached $70{ }^{\circ} \mathrm{C}$, the reaction temperature is close to the boiling point of methanol, which leads to the vaporization of a large amount of methanol. Furthermore, unexpected and uncontrollable liquid backup flooding was also observed (Gui et al., 2016). So the optimum reaction temperature for the transesterification reaction is $60^{\circ} \mathrm{C}$.

\section{Effect of Catalyst Amount on FAME Yield}

The effect of the amount of $5 \mathrm{Ce} / \mathrm{Kaolin}$ clay, ranging from 5 to $20 \mathrm{~g}$, on the FAME yield was studied for the transesterification reaction (Figure 11). According to the previous literature, a higher amount of the catalyst is essential to increase the FAME yield (Yee et al., 2011). Figure 9 shows that the yield of FAME increases with increasing catalyst amount from 5 to $15 \mathrm{~g}$, but only a slight increase of the FAME yield is observed with further increase in the catalyst amount. So $15 \mathrm{~g}$ of $5 \mathrm{Ce} / \mathrm{Kaolin}$ clay catalyst was chosen as the optimum catalyst amount for the transesterification reaction.

\section{Reusability of the Catalyst}

Reusability is regarded as the fundamental condition for manufacturing as it decreases the production cost of FAME (Alhassan et al., 2015). In order to investigate the reusability of the Ce/Kaolin clay catalyst, the transesterification of cottonseed oil was performed with methanol under optimized reaction conditions. The reusability results are presented in Figure12. As shown in Figure 10, when Ce/Kaolin clay is recycled 1, 2, 3, and 4 times, the FAME yield is $91 \%, 86 \%, 79 \%$, and $74 \%$, respectively. On increasing the number of cycles, 


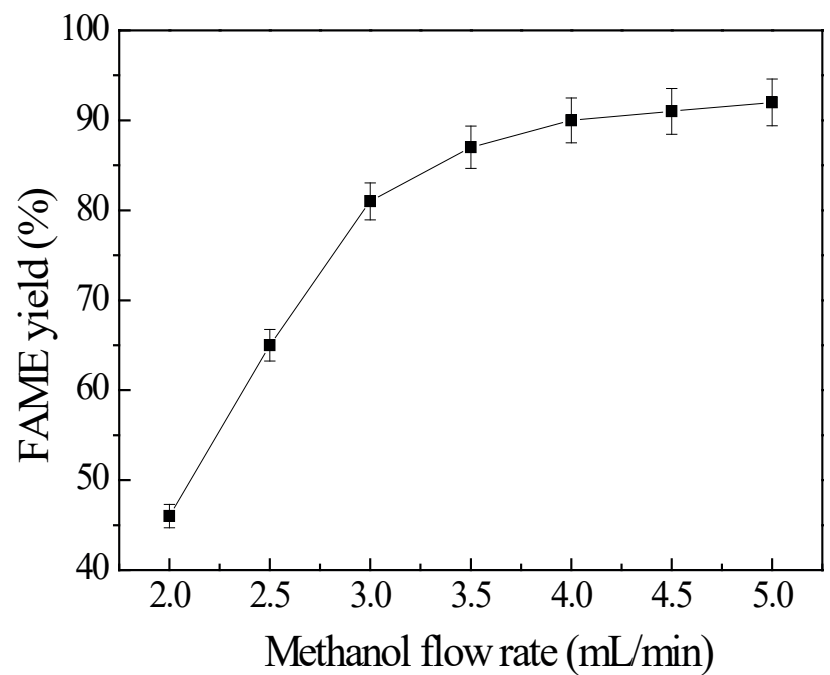

Figure 9. Influence of dosage of methanol on FAME yield. Reaction conditions: $200 \mathrm{~g}$ of cottonseed kernel powder, $15 \mathrm{~g}$ of catalyst, reaction temperature $=50^{\circ} \mathrm{C}$, and $3 \mathrm{~h}$ reaction time.

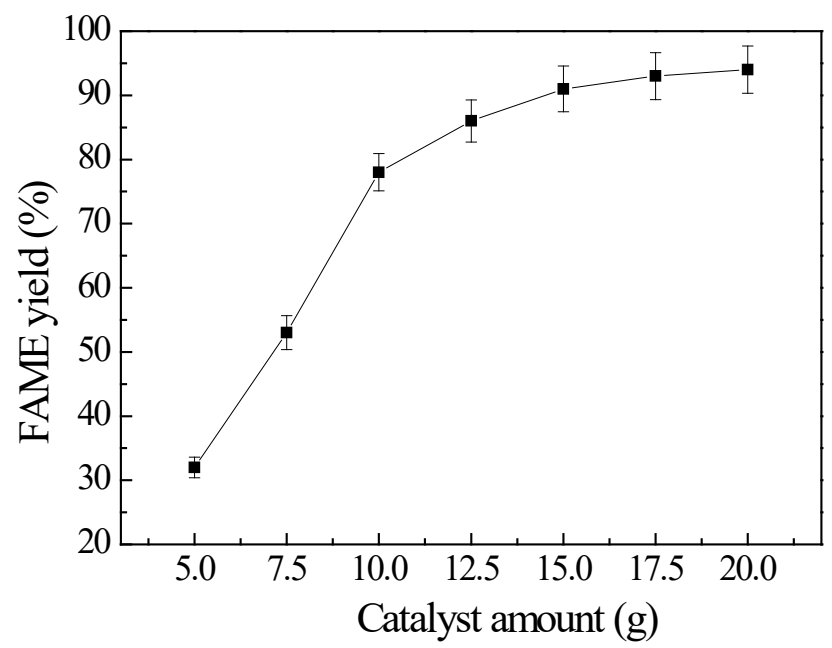

Figure 11. Influence of catalyst mass amount on FAME yield. Reaction conditions: $200 \mathrm{~g}$ of cottonseed kernel powder, $15 \mathrm{~g}$ of catalyst, $4.0 \mathrm{~mL} / \mathrm{minmethanol}$ phase rate, reaction temperature $=60$ ${ }^{\circ} \mathrm{C}$, and $3 \mathrm{~h}$ reaction time.

part of the catalysts was desquamated from the theta $(\theta)$ packing rings and the catalytic performance decreased noticeably. When the catalyst was used for five times, the FAME yield reduced to $60 \%$. The results show that the catalyst can be recycled four times without significant loss of activity.

\section{CONCLUSIONS}

An efficient solid acid catalyst (Ce/Kaolin clay) was synthesized and investigated for the extraction and transesterification of cottonseed oil to FAME in a new integrated apparatus. The results showed that the $\mathrm{Ce} /$ Kaolin clay catalysts could effectively catalyze

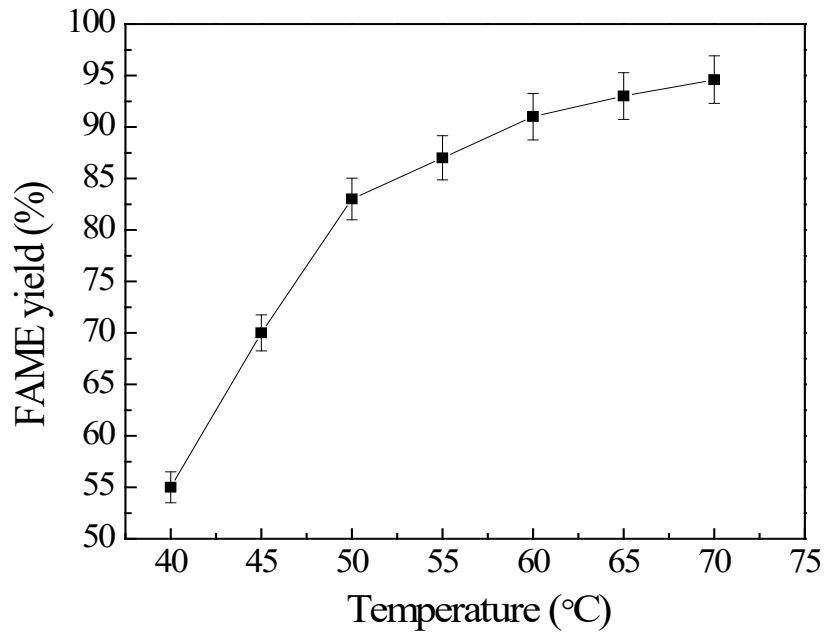

Figure 10. Influence of reaction temperature on FAME yield. Reaction conditions: $200 \mathrm{~g}$ of cottonseed kernel powder, $15 \mathrm{~g}$ of catalyst, $4.0 \mathrm{~mL} / \mathrm{minmethanol}$ phase rate, and $3 \mathrm{~h}$ reaction time.

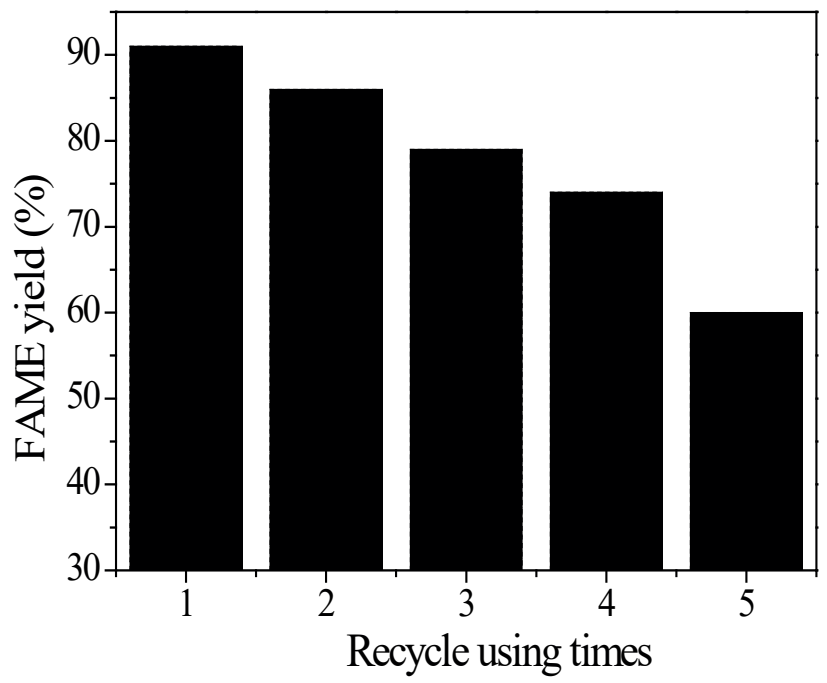

Figure 12. Reusability of the catalysts. Reaction conditions: $200 \mathrm{~g}$ of cottonseed kernel powder, $15 \mathrm{~g}$ of catalyst, $4.0 \mathrm{~mL} / \mathrm{min}$ methanol phase rate, reaction temperature $=60^{\circ} \mathrm{C}$, and $3 \mathrm{~h}$ reaction time.

cottonseed oil to produce FAME. The maximum FAME yield $(91 \%)$ was achieved under the optimal conditions of $700{ }^{\circ} \mathrm{C}$ catalyst calcination temperature, $0.05 \mathrm{~g} / \mathrm{g}$ cerium loading, $4.0 \mathrm{~mL} / \mathrm{min}$ methanol flow rate, 60 ${ }^{\circ} \mathrm{C}$ reaction temperature, $3 \mathrm{~h}$ reaction time, and $15 \mathrm{~g}$ catalyst. The results also indicated that $\mathrm{Ce} / \mathrm{Kaolin}$ clay showed an excellent catalytic stability with the yield of FAME as high as $74 \%$ after recycling for 4 times. The highest FAME yield was slightly higher than the reported literature (Silva et al., 2014) which used KF/ Clay as catalyst for FAME preparation at a yield of $89.2 \%$. These results showed that the modified Kaolin clay is a promising catalyst for the transesterification of cottonseed oil with methanol to produce FAME. 


\section{REFERENCES}

Alhassan, F. H., Rashid, U., Taufiq-Yap, Y. H., Synthesis of Waste Cooking Oil Based Biodiesel via Ferric-Manganese Promoted Molybdenum Oxide/Zirconia Nanoparticle Solid acid Catalyst: Influence of Ferric and Manganese Dopants. $J$ Oleo Sci., 64(5), 505-514 (2015).

Alves, H. J., da Rocha, A. M., Monteiro, M. R., Moretti, C., Cabrelon, M. D., Schwengber, C. A., Milinsk, M. C., Treatment of clay with KF: New solid catalyst for biodiesel production. Appl. Clay Sci., 91, 98-104 (2014).

Belviso, C., Cavalcante, F., Lettino, A., Fiore, S., A and X-type zeolites synthesised from kaolinite at low temperature. Clay Sci.,80, 162-168 (2013).

Cao, J. J., Wang, F., Fan, H., Yun, Z., Combined Production of Biodiesel and Nontoxic Cottonseed Meal Using Two-Step Two-Phase Solvent Extraction. Chem. Eng. Technol., 37(6), 1030-1036 (2014).

Dang, T. H., Chen, B. H., Lee, D. J., Application of kaolin-based catalysts in biodiesel production via transesterification of vegetable oils in excess methanol. Bioresource Technol, 145, 175-181 (2013).

Demirbas, A., Progress and recent trends in biodiesel fuels. Energy Convers Manage, 50(1), 14-34 (2009).

Gui, X., Chen, S. C., Yun, Z., Continuous production of biodiesel from cottonseed oil and methanol using a column reactor packed with calcined sodium silicate base catalyst. Chinese J. Chem. Eng., 24(4), 499-505 (2016).

Gui, X., Ding, Y., Yun, Z., Preparation of cottonseed-based epoxy fatty acid methyl esters by an integrated approach. Can. J. Chem. Eng., 94(3), 424-429 (2016).

Guo, P. M., Zheng, C., Zheng, M. M., Huang, F. H., Li, W. L., Huang, Q. D., Solid base catalysts for production of fatty acid methyl esters. Renewable Energy, 53,377-383 (2013).

Holmes, S. H., Alomair, A. A., Kovo, A. S., The direct synthesis of pure zeolite-A using 'virgin' Kaolin. RSC Adv., 2(30),1149111494 (2012).

Holmes, S. H., Khoo, S. H.,Kovo, A. S.,The direct conversion of impure natural kaolin into pure zeolite catalysts. Green Chem., 13(5),1152-1154 (2011).

Kovo, A. S., Hernandez, O., Holmes, S. H., Mater, J.,Synthesis and characterization of zeolite Y and ZSM-5 from Nigerian Ahoko Kaolin using a novel, lower temperature, metakaolinization technique. Chem.,19(34), 6207-6212 (2009).

Kuk, M. S., Tetlow, R.,Dowd, M. K., Cottonseed extraction with mixtures of acetone and hexane. J Am Oil ChemSoc, 82(8), 609-612 (2005).

Kumar, D., and Ali, A., Potassium Ion Impregnated Calcium Oxide as a Nanocrystalline Solid Catalyst for Biodiesel Production from Waste Cotton Seed Oil. Energ Source Par, 36(10), 1093-1102 (2014).
Liu, Y., Pinnavaia, T. J., Mater, J., Metakaolin as a reagent for the assembly of mesoporousaluminosilicates with hexagonal, cubic and wormhole framework structures from protofaujasitic nanoclusters. Chem., 14(23), 3416-3420 (2004).

López Granados, M., ZafraPoves, M. D., Martín Alonso, D., Biodiesel from sunflower oil by using activated calcium oxide. Appl. Catal. B-Environ., 73(3-4),317-326 (2007).

Molina Mayo, C., Brito Alayon, A. Molina Mayo, C., Brito Alayon, A., Green chromatography determination of fatty acid methyl esters in biodiesel. Environ. Sci. Technol., 36(15), 1933-1942 (2015).

Moradi, G. R., Arjmandzadeh, E., Ghanei, R., Single-Stage Biodiesel Production from Used Soybean Oil by using a Sulfuric-Acid Catalyst. Energy Technol., 1(4), 226-232 (2013).

Nascimento do, A. R., Leal Reis Alves, J. A. B., Freitas Melo de, M. A., Effect of the Acid Treatment of Montmorillonite Clay in the Oleic Acid Esterification Reaction. Mater. Res.-IberoAm . 18(2), 283-287 (2015).

Nascimento, L. F., Martins, R. F., Silva, R. F., Catalytic combustion of soot over ceria-zinc mixed oxides catalysts supported onto cordierite. J. Environ. Sci.-China,26(3), 694701 (2014)

Qian, J. F., Yun, Z., Shi, H. X., Cogeneration of biodiesel and nontoxic cottonseed meal from cottonseed processed by twophase solvent extraction. Energ. Convers. Manage., 51(12), 2750-2756 (2010).

Semwal, S., Arora, A. K., Badoni, R. P., Tuli, D. K., Biodiesel production using heterogeneous catalysts. Bioresour. Technol., 102(3), 2151-2161 (2011).

Shen, B., Wang, P., Yi, Z., Zhang, W., Tong, X., Liu, Y., Guo, Q., Gao, J., Xu, C., Synthesis of Zeolite beta from Kaolin and Its Catalytic Performance For FCC Naphtha Aromatization. Energy \& Fuels, 23(1),60-64 (2009).

Silva, L. C. A., Silva, E. A., Monteiro, M. R., Silva, C., Teleken, J.G., Alves, H.J., Effect of the chemical composition of smectites used in KF/Clay catalysts on soybean oil transesterification into methyl esters. Applied Clay Science 102, 121-127 (2014).

Wong, Y. C., Tan, Y. P., Taufiq-Yap, Y. H., Ramli, I., Tee, H. S., Biodiesel production via transesterification of palm oil by using $\mathrm{CaO}-\mathrm{CeO}_{2}$ mixed oxide catalysts. Fuel, 162, 288-293 (2015).

Yee, K. F., Lee, K. T., Ceccato, R., Production of biodiesel from Jatropha curcas $L$. oil catalyzed by $\mathrm{SO}_{4}^{2-} / \mathrm{ZrO}_{2}$ catalyst: effect of interaction between process variables. Bioresource Technol., 102(5), 4285-4289 (2011).

Zhu, Q. L., Shao, R., Dong, R., Yun, Z. An integrated approach for obtaining biodiesel, sterols, gossypol, and raffinose from cottonseed on a biorefinery concept. Energy, 70, 149-158 (2014). 